\title{
Commentary: Triggering Receptor Expressed on Myeloid Cells-1 Inhibitor Targeted to Endothelium Decreases Cell Activation
}

\author{
Alexander B. Sigalov* \\ SignaBlok, Inc., Shrewsbury, MA, United States
}

Keywords: TREM-1, sepsis, SCHOOL model of receptor signaling, ligand-independent inhibition, TREM-1 inhibitory SCHOOL peptides

\section{A Commentary on}

Triggering Receptor Expressed on Myeloid Cells-1 Inhibitor Targeted to Endothelium Decreases Cell Activation

by Gibot, S., Jolly, L., Lemarié, J., Carrasco, K., Derive, M., and Boufenzer, A. Front. Immunol. (2019)

OPEN ACCESS

Edited by:

Pietro Ghezzi,

Brighton and Sussex Medical School,

United Kingdom

Reviewed by:

Markus Philipp Radsak,

University Medical Centre, Johannes Gutenberg University Mainz, Germany

Vikrant Rai,

Creighton University School of

Medicine, United States

*Correspondence:

Alexander B. Sigalov

sigalov@signablok.com

Specialty section:

This article was submitted to

Inflammation,

a section of the journal

Frontiers in Immunology

Received: 23 November 2019

Accepted: 22 January 2020

Published: 11 February 2020

Citation:

Sigalov AB (2020) Commentary:

Triggering Receptor Expressed on

Myeloid Cells-1 Inhibitor Targeted to

Endothelium Decreases Cell

Activation. Front. Immunol. 11:173.

doi: 10.3389/fimmu.2020.00173
10:2314. doi: 10.3389/fimmu.2019.02314

Triggering receptor expressed on myeloid cells-1 (TREM-1), an inflammation amplifier, first reported in 2000 (1) was initially demonstrated to play a role in sepsis (2). Currently, the crucial pathophysiological role of TREM-1 is defined not only in infectious diseases but also in both acute and chronic forms of aseptic inflammation (3) as well as in different types of cancer $(4,5)$. Examples are ischemia-reperfusion, hemorrhagic shock, pancreatitis, spinal cord injury, inflammatory bowel diseases, rheumatic diseases, retinopathy, liver diseases, atherosclerosis, psoriasis, cystic fibrosis, Parkinson's disease, lung cancer, pancreatic cancer, liver cancer, and colon cancer. This implicates TREM-1 as a new, highly promising multi-indication therapeutic target.

Conventional TREM-1 inhibitors such as either TREM-1 inhibitory peptides LP17 and LR12 first reported in 2006 (6) and 2013 (7), respectively, or an antibody against TREM-1 first reported in 2016 (8), all attempt to block the receptor binding to its ligand(s). However, the actual nature of the TREM-1 ligand(s) is still uncertain, emphasizing the hurdles that need to be overcome before TREM-1-targeted therapy can become a clinical reality.

To address this problem, we applied our model of receptor-mediated transmembrane signaling, the Signaling Chain HOmoOLigomerization (SCHOOL), first published in $2004(9,10)$ to rationally design TREM-1-specific inhibitory peptide sequence(s) (SCHOOL peptides/sequences) that employ a novel, ligand-independent mechanism of TREM-1 inhibition. We then successfully demonstrated high efficacy of these peptides/sequences in a variety of in vitro and in vivo studies (Table 1). Recently, therapeutic efficacy of the SCHOOL peptides/sequences has been independently confirmed in a mouse model of liver cancer [(15); Table 1].

The recently published manuscript by Gibot et al. (16) describes the use of ligand-independent modulation of TREM-1 to reduce lipopolysaccharide (LPS)-induced cell activation and confer protection during experimental sepsis in mice. To inhibit TREM-1 in a ligand-independent manner, the authors used a peptide sequence LSKSLVF (Table 1), which they claimed they rationally designed.

In this regard, we thought it proper to remind the readership of Frontiers in Immunology of our pioneering study of 2014 that demonstrated the therapeutic effect of a first-in-class ligand-independent TREM-1 inhibitory peptide sequence GLLSKSLVF (mouse TREM-1-specific 
TABLE 1 | Published in vitro and in vivo studies of TREM-1 inhibitory peptide sequences that employ a ligand-independent molecular mechanism of TREM-1 inhibition (SCHOOL inhibitors).

\begin{tabular}{|c|c|c|c|c|c|}
\hline Sequence & Origin* & In vitro studies ${ }^{\star \star}$ & Animal model & Year & References \\
\hline GLLSKSLVF & mTREM-1210-218 & LPS-stimulated cells & $\begin{array}{l}\text { Sepsis } \\
\text { Non-small cell lung cancer }\end{array}$ & 2014 & $(11)$ \\
\hline GFLSKSLVF & hTREM-1213-221 & - & Collagen-induced arthritis & 2017 & $(12)$ \\
\hline GFLSKSLVF & hTREM-1 $213-221$ & - & Pancreatic cancer & 2017 & $(4)$ \\
\hline GFLSKSLVF & hTREM-1 $1213-221$ & - & Oxygen-induced retinopathy & 2018 & (13) \\
\hline GFLSKSLVF & hTREM-1213-221 & - & Alcohol-induced liver disease & 2019 & $(14)$ \\
\hline GFLSKSLVF & hTREM-1 $1213-221$ & - & Liver cancer & 2019 & $(15)$ \\
\hline LSKSLVF & hTREM-1 $215-221$ & LPS-stimulated cells & Sepsis & 2019 & $(16)$ \\
\hline
\end{tabular}

*mTREM-1, mouse TREM-1; hTREM-1, human TREM-1.

${ }^{\star \star}$ LPS, lipopolysaccharide.

SCHOOL peptide) in experimental sepsis [(11); Table 1]. In this study, we presented for the first time, direct evidences that GLLSKSLVF suppresses TREM-1-mediated production of proinflammatory cytokines TNF- $\alpha$, IL- $1 \beta$, and IL- 6 both in vitro (LPS-stimulated cells) and in vivo (LPS-challenged mice) as well as significantly prolongs survival of mice with LPS-induced septic shock (11). We specifically demonstrated that a control peptide (GLLSGSLVF) with single amino acid substitution of functionally important lysine (highlighted in bold type in Table 1) for glycine does not exhibit TREM-1 inhibitory effect, as it has been predicted by the SCHOOL model $(10,11)$.

We note that the paper by Gibot et al. does not refer to this previously published work (11). It should be also noted that in our another study, one of the cancer studies cited [Shen and Sigalov (4) in the paper by Gibot et al. (16)], we used a ligandindependent human TREM-1 inhibitory peptide GFLSKSLVF (GF9), not peptide LR12, to suppress tumor growth and prolong survival of mice with experimental pancreatic cancer (4).

\section{REFERENCES}

1. Bouchon A, Dietrich J, Colonna M. Cutting edge: inflammatory responses can be triggered by TREM-1, a novel receptor expressed on neutrophils and monocytes. J Immunol. (2000) 164:4991-5. doi: 10.4049/ jimmunol.164.10.4991

2. Bouchon A, Facchetti F, Weigand MA, Colonna M. TREM-1 amplifies inflammation and is a crucial mediator of septic shock. Nature. (2001) 410:1103-7. doi: 10.1038/35074114

3. Tammaro A, Derive M, Gibot S, Leemans JC, Florquin S, Dessing MC. TREM-1 and its potential ligands in non-infectious diseases: from biology to clinical perspectives. Pharmacol Ther. (2017) 177:81-95. doi: $10.1016 /$ j.pharmthera.2017.02.043

4. Shen ZT and Sigalov AB. Novel TREM-1 inhibitors attenuate tumor growth and prolong survival in experimental pancreatic cancer. Mol Pharm. (2017) 14:4572-82. doi: 10.1021/acs.molpharmaceut.7b00711

5. Nguyen AH, Berim IG, Agrawal DK. Chronic inflammation and cancer: emerging roles of triggering receptors expressed on myeloid cells. Expert Rev Clin Immunol. (2015) 11:849-57. doi: 10.1586/1744666X.2015.1043893

6. Gibot S, Alauzet C, Massin F, Sennoune N, Faure GC, Bene MC, et al. Modulation of the triggering receptor expressed on myeloid cells-1 pathway during pneumonia in rats. J Infect Dis. (2006) 194:975-83. doi: 10.1086/506950

7. Derive M, Boufenzer A, Bouazza Y, Groubatch F, Alauzet C, Barraud D, et al. Effects of a TREM-like transcript 1-derived peptide
In summary, we believe that it is important that our novel and clinically relevant ligand-independent approach to modulation of diverse immune receptors including TREM-1 [recently reviewed in Sigalov (17)] attracts more and more attention from the scientific and industrial community.

\section{AUTHOR CONTRIBUTIONS}

AS conceived and wrote the manuscript.

\section{FUNDING}

This work was supported by grants R43GM128369 from the National Institute of General Medical Sciences (NIGMS), R43EY028779 from the National Eye Institute (NEI), and R44CA217400 from the National Institute of Cancer (NCI). NIGMS, NEI, and NCI are components of the National Institutes of Health (NIH).

during hypodynamic septic shock in pigs. Shock. (2013) 39:176-82. doi: 10.1097/SHK.0b013e31827bcdfb

8. Brynjolfsson SF, Magnusson MK, Kong PL, Jensen T, Kuijper JL, Hakansson $\mathrm{K}$, et al. An antibody against triggering receptor expressed on myeloid cells 1 (TREM-1) dampens proinflammatory cytokine secretion by lamina propria cells from patients with IBD. Inflamm Bowel Dis. (2016) 22:1803-11. doi: 10.1097/MIB.0000000000000822

9. Sigalov AB. Multichain immune recognition receptor signaling: different players, same game? Trends Immunol. (2004) 25:583-9. doi: 10.1016/ j.it.2004.08.009

10. Sigalov AB. Immune cell signaling: a novel mechanistic model reveals new therapeutic targets. Trends Pharmacol Sci. (2006) 27:518-24. doi: 10.1016/j.tips.2006.08.004

11. Sigalov AB. A novel ligand-independent peptide inhibitor of TREM1 suppresses tumor growth in human lung cancer xenografts and prolongs survival of mice with lipopolysaccharide-induced septic shock. Int Immunopharmacol. (2014) 21:208-19. doi: 10.1016/j.intimp.2014.05.001

12. Shen ZT, Sigalov AB. Rationally designed ligand-independent peptide inhibitors of TREM-1 ameliorate collagen-induced arthritis. J Cell Mol Med. (2017) 21:2524-34. doi: 10.1111/jcmm.13173

13. Rojas MA, Shen ZT, Caldwell RB and Sigalov AB. Blockade of TREM-1 prevents vitreoretinal neovascularization in mice with oxygeninduced retinopathy. Biochim Biophys Acta. (2018) 1864:2761-8. doi: 10.1016/j.bbadis.2018.05.001 
14. Tornai D, Furi I, Shen ZT, Sigalov AB, Coban S, Szabo G. Inhibition of triggering receptor expressed on myeloid cells 1 ameliorates inflammation and macrophage and neutrophil activation in alcoholic liver disease in mice. Hepatol Commun. (2019) 3:99-115. doi: 10.1002/hep4.1269

15. Wu Q, Zhou W, Yin S, Zhou Y, Chen T, Qian J, et al. Blocking triggering receptor expressed on myeloid cells-1-positive tumor-associated macrophages induced by hypoxia reverses immunosuppression and anti-programmed cell death ligand 1 resistance in liver cancer. Hepatology. (2019) 70:198-214. doi: 10.1002/hep.30593

16. Gibot S, Jolly L, Lemarie J, Carrasco K, Derive M, Boufenzer A. Triggering receptor expressed on myeloid cells-1 inhibitor targeted to endothelium decreases cell activation. Front Immunol. (2019) 10:2314. doi: 10.3389/ fimmu.2019.02314
17. Sigalov AB. Targeting intramembrane protein-protein interactions: novel therapeutic strategy of millions years old. Adv Protein Chem Struct Biol. (2018) 111:61-99. doi: 10.1016/bs.apcsb.2017.06.004

Conflict of Interest: AS is employed by SignaBlok, Inc., a company developing ligand-independent TREM-1 inhibitors.

Copyright $(2020$ Sigalov. This is an open-access article distributed under the terms of the Creative Commons Attribution License (CC BY). The use, distribution or reproduction in other forums is permitted, provided the original author(s) and the copyright owner(s) are credited and that the original publication in this journal is cited, in accordance with accepted academic practice. No use, distribution or reproduction is permitted which does not comply with these terms. 